\title{
Intimate Partner Violence and Associated Factors among Married Women live in Hosanna Town, Southern Ethiopia
}

Tigist Temesgen ( $\nabla$ tigistergish@gmail.com )

https://orcid.org/0000-0002-4670-2812

Kedir Teji

Haramaya University College of Health and Medical Sciences

Merga Dheresa

Haramaya University College of Health and Medical Sciences

Agezegn Asegid

Wachemo University

Research article

Keywords: Intimate partner violence, associated factors, women, Hossana, Ethiopia

Posted Date: September 11th, 2019

DOI: https://doi.org/10.21203/rs.2.14281/v1

License: (c) (i) This work is licensed under a Creative Commons Attribution 4.0 International License.

Read Full License 


\section{Abstract}

\section{ABSTRACT}

Background: Intimate partner violence is a problem of pandemic proportion affecting majority of world women the literature shows that pattern and underlying cause of women violence have sociodemographic and cultural difference is common in most parts of Ethiopia. To best of investigator knowledge no studies done on intimate partner violence on married women of reproductive age group in the study area. Therefore the aim of this study is to assess the intimate partner violence prevalence and its associated factors.

Methods: A community based cross-sectional study design was used from March 1-15/2019 among 602 married women of Hosanna town Sothern Ethiopia. Systematic random sampling technique was used to select the study samples. Data were collected using pretested structured questionnaire, data entered into Epi-data version 3.1 software and exported to SPSS version 20 for analysis. Binary and multivariate logistic regressions were used to identify factors associated with intimate partner violence.

Results: The prevalence of overall intimate partner violence among married women was $58.8 \%$ ( 54.862.4). Of which $45.3 \%$ reported psychological violence, while $38.1 \%$ of participant reported sexual violence. Partners who drink alcohol [(AOR=1.44, 95\% Cl=1.133-2.09)], Partner's smoke cigarettes [(AOR=4.16, $\mathrm{Cl}=2.117-8.20)]$, partner's experience of Fighting habit with other people [(AOR=1.56 $\mathrm{Cl}=1.06$ 2.29), Has another wife[(AOR=1.60 $\mathrm{Cl}=1.09-2.36)]$, low wealth index household [( $\mathrm{AOR}=2.97 \mathrm{Cl}=1.41-6.27)]$, and medium wealth index households $[(A O R=2.636 \mathrm{Cl}=1.173-5.920)]$ were significantly associated with intimate partner violence.

Conclusion: Study indicated that prevalence of intimate partner violence found to be high and affected by various factors. The problem sought harmonious urgent attention at all levels of societal hierarchy including policymakers, local leader, institutions and local community gathering and structures.

Key words : Intimate partner violence, associated factors, women, Hossana, Ethiopia

\section{Background}

Intimate partner violence(IPV) is any behavior within an intimate relationship that causes physical, psychological or sexual harm to those in the relationship(Deribe K. et al., 2012). In another statement, it is any act of gender-based violence that results in physical harm or suffering to women, including threats of such acts, coercion or arbitrary deprivation of liberty, whether occurring in public or in private life(Barreda O. et al., 2013). This worse practice apart from affecting physical and mental well-being of women's, the impact of Violence Against Women(VAW) can be worse and affects women's productivity, quality of life, the health and development of children, families, and communities at large(Wakefield S., 2017). 
UN calls the IPV as pandemic problem of the globe affecting $35 \%$ of women in the world. As response UN call global action for decreasing this problem, which have organized package to be implemented by state government bodies at various level Again from the era of Millennium Developmental Goal (MDG) to now sustainable development goal, the UN giving due emphasis for women related activities. More over the following statement which posted on official website of UN indicates that how much global response are intense and issue is cross cutting. Specifically, the goal five of sustainable developmental goal specifically address ending of violence against women and girl. More over achievement of goal five enable achievement of goal three, four, and eight (UNODC, 2018).

Ethiopia has put in place appropriate and effective legal and policy provisions to promote the rights of women and girls by integrating statement in constitution and ratified many of the international and continental agreements that promote and protect women's rights, including the Convention on the Elimination of Discrimination against Women (CEDAW), and the Protocol to the African Charter on the Rights of Women in Africa in 1995. In addition, Ethiopia has established specific legal measures and actions to address violence, including the Revised Family Law in 2000 and the Revised Criminal Code in 2005(Negarit Gazeta, 2000). The ratification on national policy of women started in 1993, and promulgation in new constitution in 1994 which have been used as a land mark instrument to protect women against any form of violence (WHO, 2013).

Globally, almost one third (30\%) of women who have been in a relationship report that they have experienced some form of violence like physical and sexual violence by their intimate partner in their lifetime(Moreno G. et al., 2006). Again $38 \%$ of murders of women are committed by a male intimate partner (WHO, 2017). Particularly, in sub Saharan Africa, domestic and marital violence is highly prevalent and the magnitude of poor health outcomes due to intimate partner and those associated with many other better-known health risk factors(WHO, 2010).

Despite many legal framework and action at global, continental and national level the prevalence doesn't show significant change. A multi countries study on VAW in 10 different countries confirmed that the lifetime and current (past 12 months) prevalence of psychological or physical or sexual violence ranges between $15 \%$ to $71 \%$ and $4-54 \%$ respectively with the lowest rates have been found in Japan and the highest in Peru, Bangladesh and Ethiopia.(Abeya S. et al., 2011). Again, other a multi-countries study indicated that there is the highest prevalence in Ethiopian region (71\%) (WHO, 2010).

In study done in other areas of the country, various factors are identified as predictors and associated factors of intimate partner violence. Daily alcohol consumption, having affairs, fighting with other men, his mother having experienced spousal abuse and he himself being beaten as a child,female headed households were at increased likelihood to have lifetime intimate partner violence(Sepideh Hajian, 2014). On the other hand, abduction, Polygamy, spousal hostility and previous witnesses of parental violence were factors associated with an increased likelihood of lifetime intimate partner violence against women. (Sileshi G Abeya, 2011, Tanya Abramsky, 2011). 
As a result informing the leaders and mobilization of resource for tackling the problem needs scientific justification through research. Since there is no study in the study area, and administrators also declaring the decrement of violence due to misperception about the condition and scope of the problems, this study will help to bring onboard the existing prevalence and extent of problem in the study area.

Even though, 39\% of IPV kept silent at their scene(WHO,2005), promoting gender equalities, school initiatives, community and media interventions are areas have been identified to prevent IPV and can alter gender norms and promote women's rights(WHO, 2009).

The prevalence of IVP in Ethiopia varies: physical from $32.2 \%$ (Yigzaw T et al., 2004) to 47.83\%(Henok A et al., 2015); sexual from 19.2\&(Yigzaw T et al., 2004) to 49.1\%( Semahegn A et al., 2013); and similar fashion of physical abuse were reported. Accordingly undelaying factor leading to the practice also varied. To have specific intervention for the area, the context needs to be addressed with scientific procedure.

Since the occurrence and impacts of intimate partner violence is frequently "hidden" resulting in a significant under estimation of the real level of harm caused. Understanding the prevalence and factors associated with intimate partner violence is important for study area for decreasing the challenge and improve health of women. Also, the finding from this study helps to advocate women right by showing its prevalence in local community, recommend ways to encourage women in intimate partner violence to experience early identification and seek help for the safety and well-being of themselves and their children. Again for women, this study may benefit them to exercise their legal rights by seeking attention to the issue through bolding of the prevalence of problem to the concerned body. Stakeholders working on women, understanding magnitude of the problem and factors associated with of IPV may have strong implication in planning for future intervention. Health care professional also can take finding of the study for planning community service and routine activity.

After review of literature and analysis of variables under investigations the conceptual framework was created. Accordingly the direction of the arrow and arrangement shows relationship and directions of influence among variables (see figure 1).

Figure 1: Conceptual framework intimate partner violence among women live in hosanna town, 2019

Objectives

The objective of this study is to assess prevalence of Intimate partner violence and associated factors among married women.

\section{Methods}

\section{Study Design and data collection}


Community based cross-sectional study design was used to collect information from selected married women of Hosanna town which is capital of Hadiya Zone, $232 \mathrm{Km}$ South west of Addis Ababa, the capital city of Ethiopia. In Hosanna town there are 4 health centers, one teaching University hospital, sixteen private clinics and twenty four drug shops. The administrative structured of town divided into in 8 urban kebeles. Accordingly, Hosanna town population was estimated to be: male 59, 4096 and female 57, 7035. There are NGOs working on women related issue in the town like USAID, and Marie stops international. Ethical clearance was obtained from Institutional Health Research Ethics review committee (IHRERC) of Haramaya University, College of Health and Medical sciences with Ref No. IHRERC/065/2019. The permission was obtained from Hadiya zone, Hosanna town administration office which was communicated to each kebeles enrolled in the study. Informed voluntary written and signed consent was obtained after informing the purpose and importance of the study. Data was collected at household level by trained eight Nurse assistant and two a baccalaureate Nurses as supervisors.

\section{Sample Size and procedure}

Single population proportion formula was used to have total sample size of 602 with estimated prevalence of intimate partner violence of $61.2 \%$ from Sidama Zone(Regassa, 2012), 95\% confidence interval and $10 \%$ none response rate. Then total sample of participant drown from four kebeles randomly selected from 8 kebeles in the town (Hossana town Health office report, 2018). Proportional allocation to the total number of reproductive women number in each kebele used to estimate the final proportion contributed from each kebeles. Then the households in each Kebele was selected by systematic random sampling method $\left(\mathrm{N} / \mathrm{n}=\mathrm{K}^{\text {th }}\right)$ i.e., 5502/602, $\mathrm{K}=9$. Using sampling frame and simple random sampling was employed to select first house from one to nine for each kebeles. From each house hold, married reproductive age women's were selected for interview. Women's who was critically ill and unable to communicate excluded from the study.

\section{Study instruments}

The data were collected using structured and pretested questionnaire which is emanated and modified from different literature, (CSA and ISF, 2016, Agumasie S. et al., 2013). The adapted questionnaires were modified and contextualized to fit the local situation and the research objective. The questionnaires was initially prepared in English and then translated into Amharic and Hadiyisa language. The back translated to English by bilingual experts 'to keep the consistency of the questionnaires. The data collection tool consists of 53 questions categorized into five aspects: socio-demographic (nine questions); partner characteristics (nine questions); intimate partner violence (Eight questions); decision making power (nine questions) and economic status having 18 questions.

\section{Data Quality Control}


Getting Ethical clearance approval, translation and back translation of tool, training of data collectors, pre-testing over 30 questionnaires, morning discussion with data collector and daily monitoring of completeness of collected information were efforts made to maintain quality of the study.

\section{Data Analysis}

All collected data was checked for its completeness and consistence before coding and analysis. The data was entered to EPIDATA 3.1 statistical software and cleared for implausible and missed values accordingly. All data were analyze using computerize statistical software program using SPSS version 20. Multi co-linearity test was carried out to see the correlation between independent variables. Both bivariate and multivariate logistic regression models were used to identify factors associated with the outcome variable. Adjusted Odds Ratio was estimated to measure the strength of the association between dependent and independent variables. Levels of statistical significance were considered at $\mathrm{p}$ value less than 0.05 with $95 \%$ confidence interval.

\section{Results}

\section{Socio-demographic and economic characteristics}

From total of 602 expected to participate in the study 585 respondents were interviewed making response rate of $97 \%$. The mean age of the participants was 25.91 (SD \pm 3.8 years). The majority were age $25-$ 34(53.3. \%); house wife 275(47\%); attend secondary education 368(62.9\%); have husband with college and above education 231(39.5) and merchant 192(32.1\%) (Table 1).

Table 1: Biographic characteristics of married women in Hosanna town Southern Ethiopia, March $2019 \mathrm{n}$ $=585$ 


\begin{tabular}{|c|c|c|c|}
\hline variables & Categories & Frequency & Percentage (\%) \\
\hline \multirow[t]{2}{*}{ Age } & $15-24$ & 273 & 46.7 \\
\hline & $25-34$ & 312 & 53.3 \\
\hline \multirow{3}{*}{ Occupation } & Housewife & 275 & 47.0 \\
\hline & daily laborer & 155 & 26.5 \\
\hline & Merchant & 155 & 26.5 \\
\hline \multirow[t]{4}{*}{ Education } & no education & 86 & 14.7 \\
\hline & $1-8$ & 69 & 11.8 \\
\hline & $9-10$ & 368 & 62.9 \\
\hline & 10above & 62 & 10.6 \\
\hline \multirow[t]{4}{*}{ Religion } & Protestant & 213 & 36.4 \\
\hline & Orthodox & 109 & 18.6 \\
\hline & Muslim & 208 & 35.6 \\
\hline & Catholic & 55 & 9.4 \\
\hline \multirow[t]{4}{*}{ Ethnicity } & Hadiya & 214 & 36.6 \\
\hline & Kambata & 142 & 24.3 \\
\hline & Amhara & 127 & 21.7 \\
\hline & Gurage & 102 & 17.4 \\
\hline \multirow[t]{2}{*}{ Partner age } & $18-35$ & 451 & $77.1 \%$ \\
\hline & $36-60$ & 134 & $22.9 \%$ \\
\hline \multirow[t]{3}{*}{ Partner education } & $1-8$ grade & 177 & $30.3 \%$ \\
\hline & $9-10$ grade & 177 & $30.3 \%$ \\
\hline & $>10$ grade & 231 & $39.5 \%$ \\
\hline \multirow[t]{4}{*}{ Partner occupation } & Government worker & 131 & $22.4 \%$ \\
\hline & Daily laborer & 118 & $20.2 \%$ \\
\hline & Non-governmental worker & 144 & $24.6 \%$ \\
\hline & Merchant & 192 & $32.8 \%$ \\
\hline Wealth Index & $\begin{array}{l}\text { Low } \\
\text { Medium } \\
\text { Highest }\end{array}$ & $\begin{array}{l}429 \\
117 \\
39\end{array}$ & $\begin{array}{c}73.3 \% \\
20.0 \% \\
6.7 \%\end{array}$ \\
\hline
\end{tabular}

\section{Partner related characteristics}

From all study participant $266(45.5 \%)$ reported that their partner drink alcohol, of which $14(10.1 \%)$ were drinking twice a day. Nearly quarter of study participant's husband have history of physical fight with others $137(23.4 \%)$. The majority of the respondent's partners were family history of violence $446(76.2 \%)$. Nearly one third of respondent's partners have more than one wife193 (33.0\%) (Table 2).

Table 2: Husband characteristics of intimate partner violence among married women in Hosanna town Southern Ethiopia, March $2019 \mathrm{n}=585$ 


\begin{tabular}{|c|c|c|c|}
\hline Partner related characteristics & Response & Frequency & Percentage \\
\hline \multirow[t]{2}{*}{ Alcohol drink $n=585$} & Yes & 266 & $45.5 \%$ \\
\hline & No & 319 & $54.5 \%$ \\
\hline \multirow[t]{4}{*}{ Haw often drank $n=266$} & once a day & 29 & $10.1 \%$ \\
\hline & twice a day & 124 & $50.1 \%$ \\
\hline & Sometimes & 30 & $8.0 \%$ \\
\hline & more than a day & 83 & $3.0 \%$ \\
\hline \multirow[t]{2}{*}{ Partner smoke cigarette $n=585$} & Yes & 78 & $13.3 \%$ \\
\hline & No & 507 & $86.7 \%$ \\
\hline \multirow[t]{2}{*}{ Haw often smoke cigarette $n=78$} & once a day & 66 & $73.2 \%$ \\
\hline & Sometimes & 12 & $26.8 \%$ \\
\hline \multirow[t]{2}{*}{ Drug user $n=585$} & Yes & 99 & $16.9 \%$ \\
\hline & No & 486 & $83.1 \%$ \\
\hline \multirow[t]{2}{*}{ Substance use $n=99$} & Shisha & 11 & $12.5 \%$ \\
\hline & Chewing chat & 88 & $87.0 \%$ \\
\hline \multirow[t]{2}{*}{ Has another wife $n=585$} & Yes & 192 & $32.8 \%$ \\
\hline & No & 393 & $67.2 \%$ \\
\hline \multirow[t]{2}{*}{ Number of wife $(n=192)$} & 1 & 175 & $29.9 \%$ \\
\hline & $>1$ & 17 & $2.9 \%$ \\
\hline \multirow[t]{2}{*}{ partener fighting with other people $n=585$} & Yes & 137 & $23.4 \%$ \\
\hline & No & 448 & $76.6 \%$ \\
\hline
\end{tabular}

\section{Women in family}

From the total of 585 participants, only 140 (23.3\%) of them had access to information about intimate partner violence and gender equality; 374(63.9\%), freedom to visit family; $199(33.0 \%)$ independently decide on child and own health; 385(65.8) contribute on house hold purchase; 185(31.6\%) decide on major house hold purchase; 77(13.2) were acting as head of house and decision making power exercised by only $130(22.2 \%)$ (see figure 2 ).

Figure 2: Family characteristic of study participant, intimate partner violence, Hosanna town, March 2019

\section{Prevalence of Intimate partner violence}

From the common forms of IPV psychological violence (45.3\%) was the predominant next to physical and sexual violence respectively (see figure 3 )

Figure 3: Forms of Intimate partner violence among married women in Hosanna town April 2019. 
The overall prevalence of IPV was estimated by asking any form of IPV in the last 12 month. Accordingly From total study participant 344(58.8\%) reported experience of some form of intimate partner violence (see figure 4).

Figure 4: Prevalence of Intimate partner violence among married women in Hosanna town April 2019.

\section{Factors associated with Intimate partner violence}

In the bivariate analysis, the covariate; Age of respondents, educational status of respondents, partner alcohol drinking behavior, head of the house hold, partner smoke cigarettes, partner drug using,partner have another wife, husband faced history of fighting habit with other people, husband family history of IPV, wealth index of the were showed significant association with intimate partner violence

In multiple logistic regression analysis by using enter method the covariates: Alcohol drinking, partner smoke cigarettes, partner has another wife, wealth index and husband faced history of fighting habit with other people, were significantly associated with intimate partner violence.

Partners who drank alcohol were 1.4 times more likely to experience IPV [(AOR $=1.44,95 \% \mathrm{Cl}=1.133-$ 2.09)]. Respondents who partner smoke cigarettes were 4 times more likely to experience Intimate partner violence $[(A O R=4.16,95 \% \mathrm{Cl}=2.117-8.20)]$.Similarly, those women whose Husband's experience of Fighting with other men were 1.5 times more likely experience of IPV[(AOR $=1.56, \mathrm{Cl}=1.06-2.29)]$. Partners who has another wife were 1.6 times more likely to experience IPV $[(A O R=1.60,95 \% \mathrm{Cl}=1.09$ 2.36)]. Additionally, low and medium economic status were 3 and 2.6 times more likely to experience Intimate partner violence than highest Economic status respectively[(AOR $=2.97,95 \% \mathrm{Cl}=1.41-6.27)][($ $\mathrm{AOR}=2.636,95 \% \mathrm{Cl}=1.173-5.920)]$

Table 5: Bivariate andMultivariable logistic regression analysis showing independent predictors of Intimate partner violence among married women in Hosanna town, Southern Ethiopia, March 2019 


\begin{tabular}{|c|c|c|c|c|c|}
\hline \multirow[t]{2}{*}{ Variable } & \multirow[t]{2}{*}{ Category } & \multicolumn{2}{|c|}{ Intimate partner violence } & \multirow[t]{2}{*}{ COR (95\% CI) } & \multirow{2}{*}{$\begin{array}{l}\mathrm{AOR} \quad(95 \% \\
\mathrm{CI})\end{array}$} \\
\hline & & Yes & No & & \\
\hline \multirow[t]{2}{*}{ Alcohol drinking } & Yes & $171(64.3 \%)$ & $95(35.7 \%)$ & $1.51\left(1.08 \_2.12\right)$ & $\begin{array}{l}1.443 \\
(1.13-2.09)\end{array}$ \\
\hline & No & $173(54.2 \%)$ & $\begin{array}{l}146 \\
(45.8 \%)\end{array}$ & 1.00 & 1.00 \\
\hline \multirow[t]{2}{*}{$\begin{array}{l}\text { Husband family } \\
\text { IPV }\end{array}$} & Yes & $313(58.3 \%)$ & $224(41.7 \%)$ & $0.766\left(0.41 \_1.41\right)$ & $\begin{array}{l}0.589(0.27- \\
1.27)\end{array}$ \\
\hline & No & $31(64.6 \%)$ & $17(35.4 \%)$ & 1.00 & 1.00 \\
\hline \multirow[t]{2}{*}{$\begin{array}{l}\text { Husband } \\
\text { physical fight }\end{array}$} & Yes & $64(46.7 \%)$ & $73(53.3 \%)$ & $0.52(0.37-0.77)$ & $\begin{array}{l}1.562 \\
(1.06-2.29) \\
*\end{array}$ \\
\hline & No & $280(62.5 \%)$ & $168(37.5 \%)$ & 1.00 & 1.00 \\
\hline \multirow[t]{2}{*}{$\begin{array}{l}\text { Head of house } \\
\text { holds }\end{array}$} & Husband & $299(58.9 \%)$ & $209(41.1 \%)$ & $1.017(0.62-1.65)$ & $\begin{array}{l}0.69(0.38- \\
1.26)\end{array}$ \\
\hline & Wife & $45(58.4 \%)$ & $32(41.6 \%)$ & 1.00 & 1.00 \\
\hline \multirow[t]{2}{*}{ partner drug use } & Yes & $67(64.4 \%)$ & $37(35.6 \%)$ & $1.334(.85-2.07)$ & \multirow{2}{*}{$\begin{array}{l}0.80(0.45- \\
1.42) \\
1.00\end{array}$} \\
\hline & No & $277(57.6 \%)$ & $204(42.4 \%)$ & 1.00 & \\
\hline \multirow[t]{2}{*}{$\begin{array}{ll}\text { partner } & \text { smoke } \\
\text { cigarette } & \end{array}$} & Yes & $66(84.6 \%)$ & $12(15.4 \%)$ & $4.531(2.39-8.58)$ & $\begin{array}{l}4.167 \\
(2.12-8.20) \\
*\end{array}$ \\
\hline & No & $278(54.8 \%)$ & $229(45.2 \%)$ & 1.00 & 1.00 \\
\hline \multirow[t]{3}{*}{ Wealth index } & low & $261(60.8 \%)$ & $168(39.2 \%)$ & $2.233(1.14-4.35)$ & $\begin{array}{l}2.979 \\
(1.42-6.27)\end{array}$ \\
\hline & Medium & $67(57.3 \%)$ & $50(42.7 \%)$ & $1.926(.92-4.02)$ & \multirow{2}{*}{$\begin{array}{l}2.636(1.17- \\
5.92) * \\
1.00\end{array}$} \\
\hline & High & $16(41.0 \%)$ & $23(59.0 \%)$ & 1.00 & \\
\hline \multirow[t]{2}{*}{ Has another wife } & Yes & $99(51.6 \%)$ & $93(41.0 \%)$ & $0.643(0.45-0.91)$ & \multirow{2}{*}{$\begin{array}{l}1.607(1.09- \\
2.36) * \\
1.00\end{array}$} \\
\hline & No & $245(562.3 \%)$ & $148(37.7 \%)$ & 1.00 & \\
\hline \multirow[t]{4}{*}{$\begin{array}{l}\text { Maternal } \\
\text { education }\end{array}$} & $\begin{array}{l}\text { No } \\
\text { education }\end{array}$ & $166(61.9 \%)$ & $102(38.1 \%)$ & $0.870(0.49-1.53)$ & $\begin{array}{l}1.45(0.70- \\
2.97)\end{array}$ \\
\hline & 1-8 grade & $50(63.3 \%)$ & $29(36.7 \%)$ & $0.922(0.47-1.82)$ & $\begin{array}{l}1.05(0.44- \\
2.47)\end{array}$ \\
\hline & $\begin{array}{l}9-10 \\
\text { grade }\end{array}$ & $85(49.4 \%)$ & $87(50.6 \%$ & $0.52(0.29-0.9)$ & \multirow{2}{*}{$\begin{array}{l}1.05(0.49- \\
2.23) \\
1.00\end{array}$} \\
\hline & $\begin{array}{l}10 \text { and } \\
\text { above }\end{array}$ & $43(65.2 \%)$ & $23(34.8 \%)$ & 1.00 & \\
\hline \multirow[t]{2}{*}{ Maternal age } & $15-24$ & $161(59.0 \%)$ & $112(41.0 \%)$ & $1.01(.72-1.410)$ & \multirow{2}{*}{$\begin{array}{l}0.82(0.54- \\
1.24) \\
1.00\end{array}$} \\
\hline & $25-34$ & $183(58.7 \%)$ & $129(41.3 \%)$ & 1.00 & \\
\hline
\end{tabular}




\section{Discussions}

The overall prevalence of Intimate partner violence among married women found to be $58.80 \%$. The current study revealed that psychological violence (45.3\%), which followed by physical (40\%) and sexual violence (38.1\%). Alcohol drinking, partner smoke cigarettes, polygamies, wealth index and husband faced history of physical fight with another man, were identified as factors associated with Intimate partner violence.

The prevalence is relatively the same as compared with the study done in, Gonder, Southeast Nigeria, Sohag Egypt, 50.8\%, 56\%, 58.1\%, and 56.9\%, respectively (Yigzaw T et al., 2004, Uzoma F. and.0I, 2017, Ali R. and Radwan R., 2017). But, it was less than findings from, East Wollega Zone, Bench Maji Zone, Agew Amhara zone 75.6, 76.5\%, 78.0\%, \%, Anolue FC, et al, 2017(Andualem H. et al., 2015, Tanya A. et al., 2011, Agumasie S. et al., 2013). The difference might be the presence cultural and traditional support gender norm that support wife beating within the community and may be due to study difference in which in the current study victim may disclose more about the occurrence of problem. At the same time, the prevalence in this study also higher as compared with study done in Northeastern Region of Iran (20\%) (Sepideh h. et al., 2014). This inconsistency could be due to the difference in the sample population used in Iran study was mainly from urban and educated group of community.

Maternal education has not statistically significant associate with intimate violence in this study, while it was reported that higher education prevents intimate physical violence(Sepideh Hajian, 2014). Again, in congruent with studies conducted in Serbia and Nigeria.(Bosiljka D. et al., 2010, Chima h. et al., 2015), this study found that woman who partner's drank alcohol were more likely to experience intimate partner violence than among those partner's not drink alcohol. This might be due to when they consume alcohol, they may have been more likely to become aggressive and the severity of violence sustained from drunken perpetrator.

Respondent's partners who smoke cigarettes were more likely to experience Intimate partner violence as compared to that respondent's partner's not smoke cigarette. This finding was parallels with study done in northeast of Iran finding (Sepideh h. et al., 2014). This is may be due to cigarette smoking may create an atmosphere of tension and also affects cognitive manuscript (Breslau N, \& Klein DF, 1999).

Those women whose partner's experience of physical Fighting with other men were more likely to experience of intimate partner violence than those women whose partners have no experience of fighting with other men. The same and consistent result was reported from study conducted in Shanghai China and Belgrade Serbia(XiaowenT. and Chaohua L 2017, Djikanovic B. et al., 2010). This consistency may be due to special distribution of underlying factors of fighting and its association with intimate partner violence may be similar across different population.

Also, this study revealed that those respondent partners who has another wife were more likely to experience intimate partner violence than among those partners who has no another wife. This finding was congruent with previous study done in Belgrade Serbia and East Wollega(Djikanovic B. et al., 2010, 
Tanya A. et al., 2011). This also helps to justify how polygamy perpetuates violence in women and affects women's reproductive health. Hence, it was described for having another wife could put women at increased risk for sexually transmitted infections together with violence contributes to psychological burden, low self-esteem, low life satisfaction, more mental symptomatology, feelings of embarrassment and humiliation(Al-Krenawi A, 2015).

Poverty and associated stress are key contributors to intimate partner violence (Jewkes R, 2002). This study found that, as level of the economic status increase the chance of intimate partner decrease and vise verse. This is contradict with finding from Fagitalekoma Woreda Awi zone where annual low income experiencing of low IPV than medium income households (Agumasie S. et al., 2013). This might be difference in underlying awareness of violence and reporting in low income populations and difference in setting of data collected. The reason might be the low income by itself creates disagreement that leads for straggle for ownership poor socioeconomic conditions contribute to violence. This finding similar with study conducted in East Wollega (Agumasie S. et al., 2013) and Nepal(Sunita Dhungel, 2017).S, 2017)

\section{Strength and limitation of the study}

Since the study conducted at community level with adequate sample it's possible to exploration or generalized to the same population

First each predictor variables assumed to be parallel and with no interaction effect, which may hide some attributed of the study population and its effect on outcome variables. Limited discussion of positive factors that can prevent intimate violence among married women and use of cross sectional design also leads to some degree of recall bias. No causal association due to study design chosen and social desirability biases due to sensitivity of the case under the study.

\section{Conclusions}

This study revealed that prevalence of intimate partner violence among married women was high. Partners who drank alcohol, partner smoke cigarettes, and husband's experience of fighting with other men, partner have another wife and low and medium households were significantly associated with the Intimate partner violence.

Despite consistent report of higher prevalence in IPV level of intervention doesn't prove decrement of the case. As result Multifaceted interventions such as male counseling, increasing awareness on the consequences of intimate partner violence and the effect alcohol drinkind,cigarate smoking, fighitng habit with other people,have another wife will help to reduce intimate partner violence. Consider issue of violence in planning, implementation, and evaluation of as a priority action develop a new strategy that increase community wareness about intimate partner violence and tackling strategy. Further study with higher level that can show causal relationship need to be conducted to convice offical at higher level.

\section{Abbreviations}


IVP: Intimate Partner Violance; AOR: Adjusted Odds Ratio; COR: Crude Odds Ratio; Cl: Confidence Interval;SD: Standard Deviation; CSA: Central statistics Agency; USAID: United State government Aid; NGO: Non Governmental Organization; WHO: World Health Organization;MDG: Mellinium Developmental Goal; UN: United Nation; CEDAW: Convention on the Elimination of Discrimination against Women; IHRERC: Institutional Health Research Ethics review committee; UNODC: United Nations Office on Drugs and Crime

\section{Declarations}

\section{Ethics approval and consent to participate}

Ethical clearance was obtained from Institutional Health Research Ethics review committee (IHRERC) of Haramaya University, College of Health and Medical sciences and granted declaration letter with Ref No. IHRERC/065/2019. First family member was informed about the study nature and purpose before mothers were asked privately.For participant having age less than 16 year written informed consent was taken from the guardian. The study participants were informed about the study, their participation was voluntary and oral consent was given before starting the interview. The respondents were assured about the confidentiality of their data.

Please provide parental consent in consent to participate

\section{Consent for publication}

Not applicable

\section{Availability of data and materials}

The data set analyzed can be accessed from corresponding authors at any time

\section{Competing interest}

The authors declare that they have no competing interest

\section{Funding}

This study got grant from Haramaya University College of Health and medical science as part of master student thesis

\section{Author's contributions}


TT: contribute to conception, design write the proposal, participate in data collection supervision, and analyze the data. KT: had revised the proposal and research report. MD: had revised the proposal and research report. AA: had revised design, the proposal, and research report and prepare the manuscript. All authors read and approved the final manuscript.

\section{Acknowledgements}

Our deep gratitude goes to Haramaya University College of Health and medical science for financial support.

\section{Author detail}

${ }^{1}$ Clinical nursing staff at Wachemo university Nigist Elleni Mohammed Memorial referral hospital

${ }^{2 a}$ Assistant professor at school of Nursing and midwifery, College of health and medical sceince in Haramaya University

${ }^{2 b}$ Assisstant professor at school of public health, College of health and medical sceince in Haramaya University

${ }^{2 c}$ Lecterur at Wachemo Univesity department of Nursing and Ph.D. Fellow at Haramaya Univesity School of Nursing and midwifery. to some degree of recall bias.n and educated group of communityve study

\section{References}

ABEYA S., AFEWORK MESGANAW F \& YALEWALEMAYEHU W 2011. Intimate partner violence against women in western Ethiopia: prevalence, patterns, and associated factors. BMC public health, 11, 913.

AGUMASIE S., BELACHEW, T. \& ABDULAHI, M. 2013. What factors are associated with recent intimate partner violence? multi-country study on women's health and domestic violence. BMC Public Health 11, 1471-2458.

ALI R. \& RADWAN R. 2017. Magnitude and determinants of domestic violence against ever married women in Sohag, Egypt. International Journal of Medical Science and Public Health, 6, 1285-1291.

ANDUALEM H., AYIWA TSEHAW, MARANATA NEGASH \& NEGASH, S. 2015. Prevalence and Consequences of Domestic Violence among Married Women in Sheybench Town, Bench Maji Zone, Southwest Ethiopia,. Department of public health, Vol.5, 13,.

BARREDA O., GABY VIVES \& CARMEN 2013. Legislation on violence against women overview of key components. SciELO Public Health. 
BOSILJKA D., JANSEN, HENRICA AFM, OTASEVIC \& STANISLAVA 2010. Factors associated with intimate partner violence against women in Serbia: a cross-sectional study. Journal of Epidemiology \& Community Health, 64, 728-735.

CHIMA H., UZOAMAKA CAROL, ILIKA, AMOBI LINUS, UBAJAKA \& CHIKA FLORENCE 2015. Factors associated with intimate partner violence among wives of military and civilian men in Abuja Nigeria. Sociology mind, 5, 61.

CSA AND ISF 2016. Ethiopia Demographic and Health Survey 2016.

DERIBE K., BEYENE BIRUK KEBEDE, TOLLA ANBESSU, MEMIAH PETER, BIADGILIGN SIBHATU \& AMBERBIR ALEMAYEHU 2012. Magnitude and correlates of intimate partner violence against women and its outcome in Southwest Ethiopia. PloS one, 7, e36189.

DJIKANOVIC B., JANSEN, HENRICA AFM, OTASEVIC \& STANISLAVA 2010. Factors associated with intimate partner violence against women in Serbia: a cross-sectional study. Journal of Epidemiology \& Community Health, 64, 728-735.

MORENO G., CLAUDIAJANSEN, AFM, H., ELLSBERG MARY, HEISE LORI \& WATTS CHARLOTTE H 2006. Prevalence of intimate partner violence: findings from the WHO multi-country study on women's health and domestic violence. The lancet, 368, 1260-1269.

REGASSA, N. 2012. Intimate partners violence in Southern Ethiopia: Examining the prevalence and risk factors in the Sidama zone. International Journal of Sociology and Anthropology, 4, 13-22.

SEPIDEH H., VAKILIAN KATAYON, NAJM-ABADI KHADIJEH MIRZAII, HAJIAN PARASTOO \& JALALIAN MEHRDAD 2014. Violence against women by their intimate partners in Shahroud in northeastern region of Iran. Global journal of health science, 6, 117.

SEPIDEH HAJIAN, K. V., KHADIJEH MIRZAII NAJM-ABADI, PARASTOO HAJIAN, MEHRDAD JALALIAN 2014. Violence against Women by Their Intimate Partners in Shahroud in Northeastern Region of Iran. Global Journal of Health Science, 6, 14.

SILESHI G ABEYA, M. F. A., ALEMAYEHU W YALEW 2011. Intimate partner violence against women in western Ethiopia: prevalence, patterns, and associated factors. BMC Public Health 11, 18.

SUNITA DHUNGEL, P. D., SHALIK RAM DHITAL, CHRISTIANE STOCK 2017. Is economic dependence on the husband a risk factor for intimate partner violence against female factory workers in Nepal? BMC Women's Health 17, 9.

TANYA A., CHARLOTTEWATTS, CLAUDIAMORENO, KARENDEVRIES, LIGIAKISS, MARYELLSBERG, HENRICAJANSEN \& LORIHEISE 2011. What factors are associated with recent intimate partner violence? Findings from the WHO multi-country study on women's health and domestic violence. BMC public health, $11,109$. 
TANYA ABRAMSKY, C. H. W., CLAUDIA GARCIA-MORENO, KAREN DEVRIES, LIGIA KISS, MARY ELLSBERG, HENRICA AFM JANSEN, LORI HEISE 2011. What factors are associated with recent intimate partner violence? findings from the WHO multi-country study on women's health and domestic violence. BMC Public Health 11, 17.

UZOMA F. \&.OI, A. 2017. Intimate partner violence: prevalence, contributing factors and spectrum among married couples in Southeast Nigeria. International Journal of Reproduction, Contraception, Obstetrics and Gynecology, 6, 3748-3753.

WAKEFIELD S. 2017. Transformative and Feminist Leadership for Women's Rights. Boston, Oxfam. Retrieved from https://www. oxfamamerica. org/explore ....

WHO 2005. Addressing violence against women and achieving the Millennium Development Goals. WHO/FCH/GWH/05. 1

WHO 2009. Promoting gender equality to prevent violence against women. 1-18.

WHO 2010. London School of Hygiene and Tropical Medicine. Preventing intimate partner and sexual violence against women: taking action and generating evidence. Geneva: World Health Organization, 94.

WHO 2013. Responding to intimate partner violence and sexual violence against women: WHO clinical and policy guidelines, World Health Organization.

XIAOWENT. \& CHAOHUA L 2017. Risk factors associated with current intimate partner violence at individual and relationship levels: a cross-sectional study among married rural migrant women in Shanghai, China. BMJ open, 7, e012264.

YIGZAW T, ANWAR Y \& K, Y. 2004. Domestic violence around Gondar in Northwest Ethiopia. J.Health Dev, 18(3), 133-139.

AL-KRENAWI A, 2015. Mental health and polygamy: The Syrian case.World J Psychiatry. 2013 Mar 22;3(1):1-7. doi: 10.5498/wjp.v3.i1.1.

WHO. 2017. Violance against women: fact sheet. November 2017. Also available on [URL:

https://www.who.int/news-room/fact-sheets/detail/violence-against-women]. Accessed on 15/07/2019.

UNODC. 2018. UN Joint Global Programme calls for coordinated, multi-sectoral responses to genderbased violence. Also available on [URL: https://www.unodc.org/unodc/en/frontpage/2018/May/un-jointglobal-programme-calls-for-coordinated-multi-sectoral-responses-to-gender-based-violence.html] accessed on July 15/2019.

Breslau N, \& Klein DF. Smoking and Panic AttacksAn Epidemiologic Investigation Arch Gen Psychiatry. 1999;56(12):1141-1147. doi:10.1001/archpsyc.56.12.1141 
Conceptual framework

\begin{tabular}{|c|c|c|}
\hline $\begin{array}{l}\text { Socio-demographic } \\
\text { characteristics } \\
\text { Partner and w omen } \\
\text { - Age } \\
\text { - Religion } \\
\text { - Ethnicity } \\
\text { - Educational status } \\
\text { - Occupational status }\end{array}$ & $\begin{array}{l}\text { Husband related characteristics } \\
\text { - Alcohol drinking } \\
\text { - Cigarette smoking } \\
\text { - Fighting habit with other people } \\
\text { - Having another wife } \\
\text { - Substance abuse } \\
\text { - Family history of IPV } \\
\text { Family related characteristics } \\
\text { - Decision making Power } \\
\text { - Head of house hold } \\
\text { - Wealth index }\end{array}$ & $\begin{array}{l}\text { Intimate } \\
\text { partner } \\
\text { violence }\end{array}$ \\
\hline
\end{tabular}

Figure 1

Conceptual framework intimate partner violence among women live in hosanna town, 2019

\section{Family Characteristics}

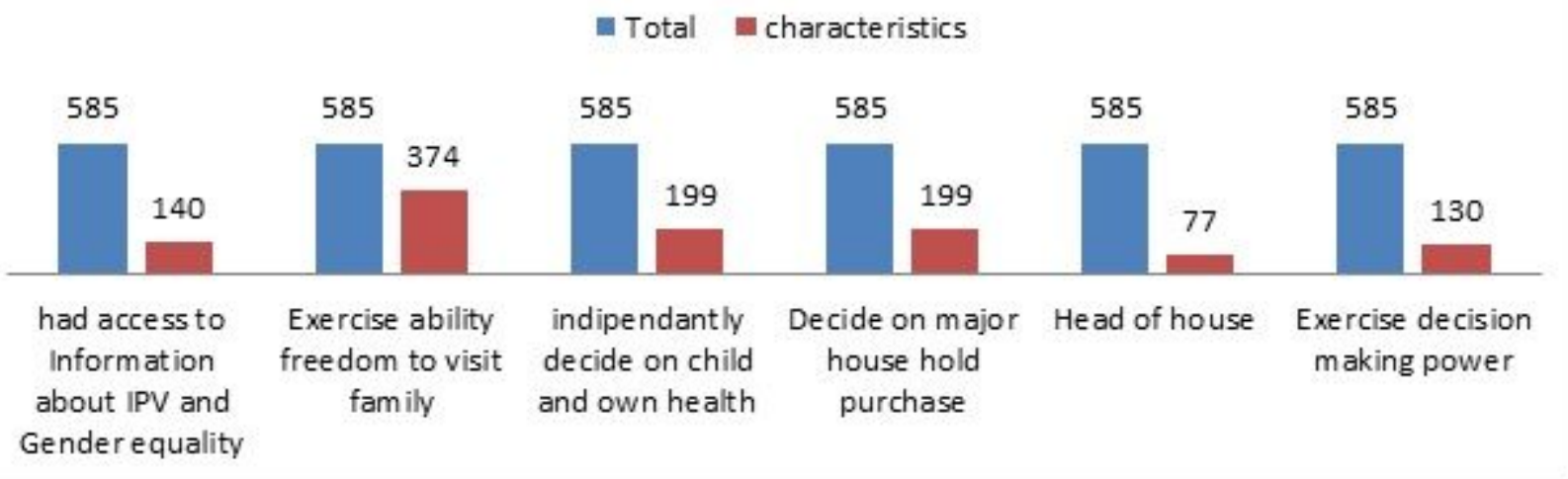

Figure 2

Family characteristic of study participant, intimate partner violence, Hosanna town, March 2019 


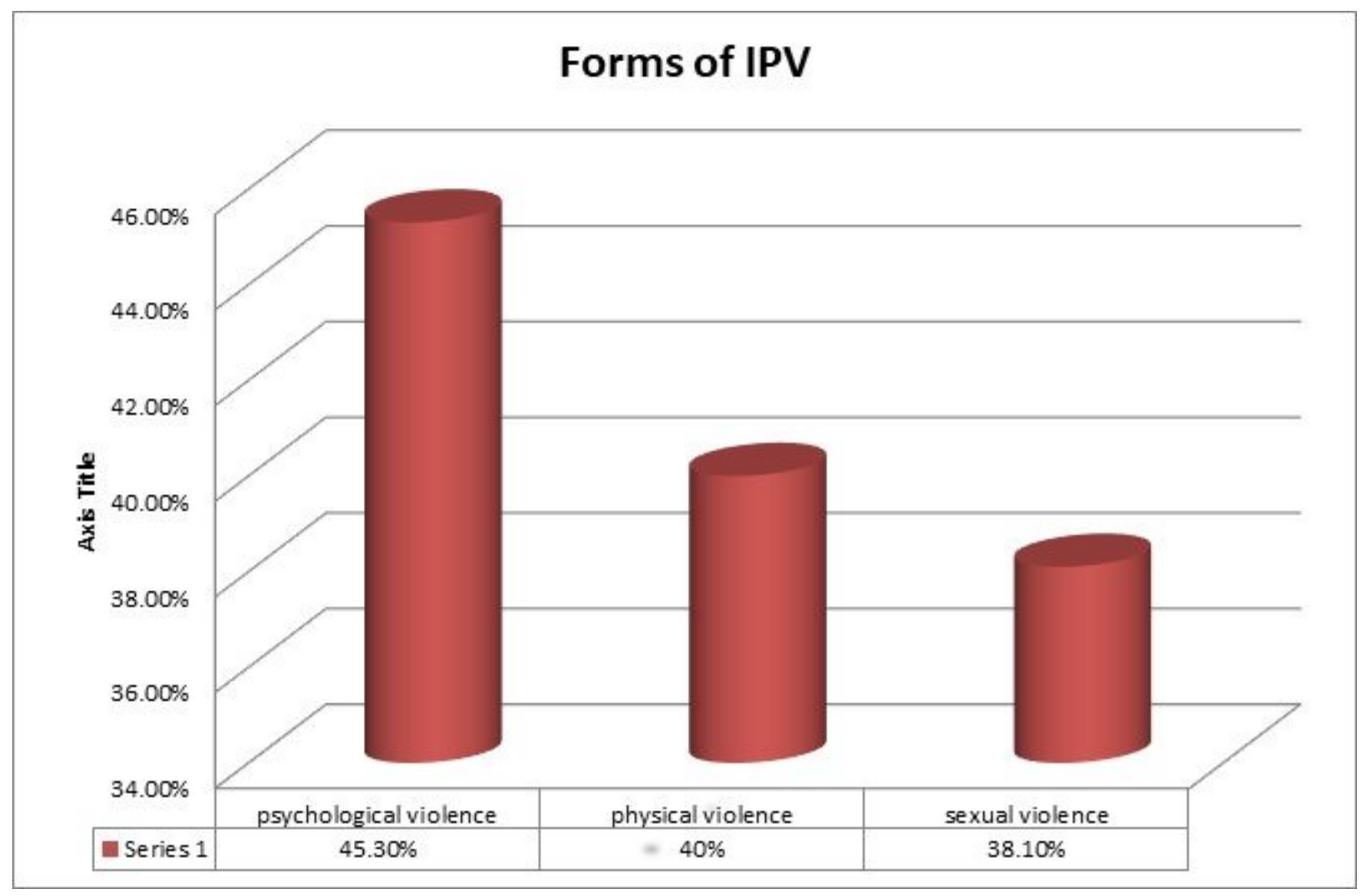

\section{Figure 3}

Forms of Intimate partner violence among married women in Hosanna town April 2019

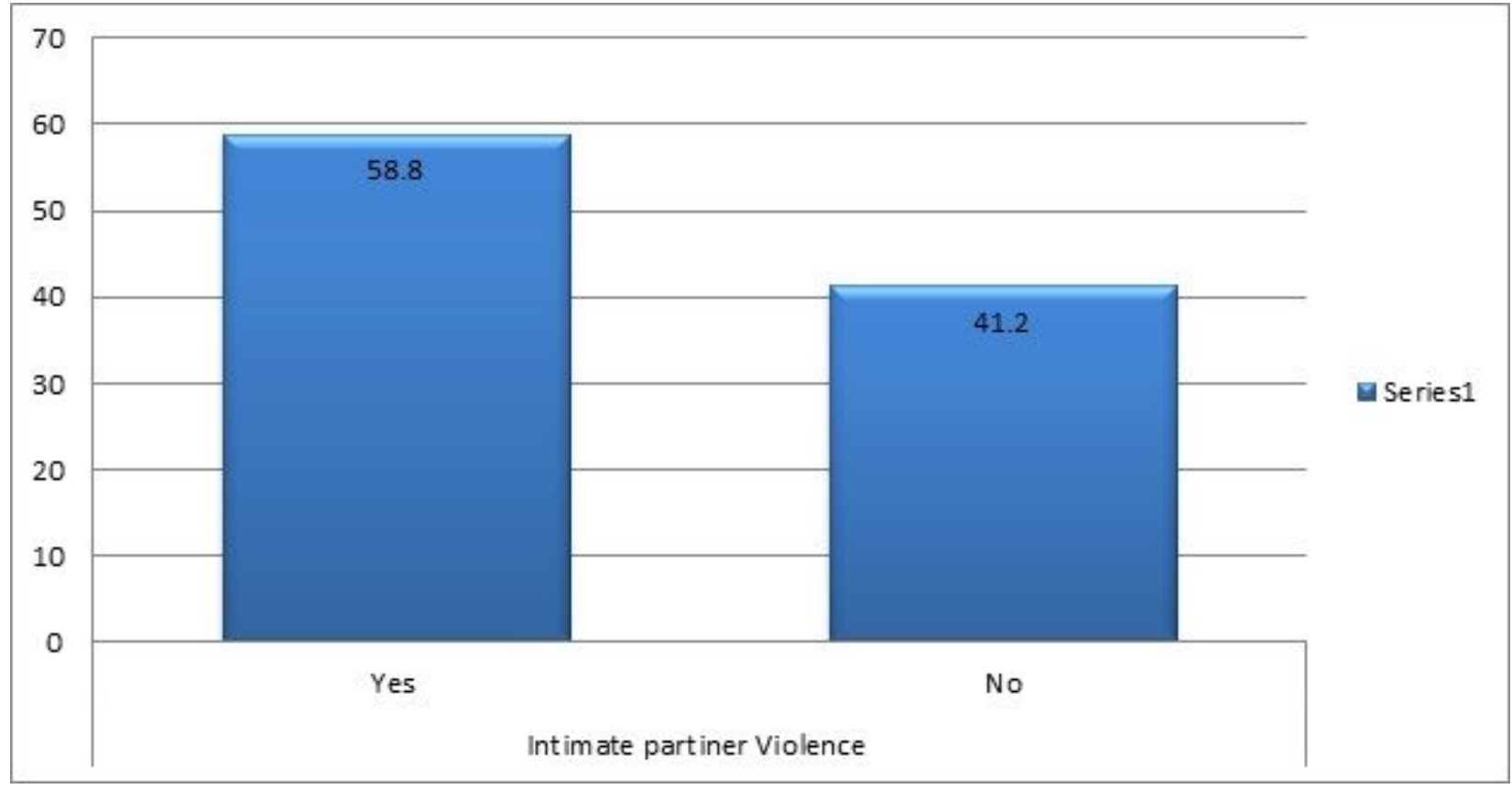

Figure 4

Prevalence of Intimate partner violence among married women in Hosanna town April 2019. 


\section{Supplementary Files}

This is a list of supplementary files associated with this preprint. Click to download.

- IPVSTROBEchecklistcrosssectional.doc 